\title{
Fair Price Shop Tracking System
}

\author{
Pooja Hulgeri $^{1}$, Pramod Shivgunde ${ }^{2}$, Rajanigandha Sangolgi ${ }^{3}$ \\ ${ }^{1}$ Shri Siddheshwar Women ${ }^{e e s ~ P o l y t e c h n i c, ~ S o l a p u r ~}$ \\ ${ }^{2,3}$ Professor, Shri Siddheshwar Womenes Polytechnic, Solapur
}

\begin{abstract}
GSM based fair price shop tracking system is an interesting GSM based project, mainly useful for fair price shops application. This project gives exact concept of stopping corruption by using a thumb detector.Basically this system is implemented by considering the need of below poverty line (BPL) card holder to get their food grain without interferes.In this project, first step is to design GSM based FPS tracking system. Thumb detector is interfaced to AT89s52. This thumb detector is used to match the fingerprint of valid customer. AT89s52 is used to store the information related to customer and GSM module is used to send the message to the higher authority. The power supply circuit is built to provide the required supply voltage to the circuit. The 7 Segment LCD display is used to display the user related information on the LCD display.
\end{abstract}

Keywords: FPS, GSM, thumb detector, AT89s52

\section{Introduction}

Many times the dealers of the grocery shops sells goods at higher prices apart from illegally having BPL ration cards. To avoid such kind of flaws and corruptions the idea of fair price shop tracking system is invented. It is one of the best tracking systems as others like vehicle, mobile tracking systems.

FPS tracking system is invented to stop the corruption done by FPS dealers who resort to malpractice illegal diversions of commodities, holding and black marketing of food grains like wheat, jowar, rice and sugar. The All India Fair Price Shop Dealer Federation (AIFPSDF) has demanded that the Indian government supply the entire allocated quota of foodgrains and other commodities to fair price shops [4].

The Indian state government's ambitious project involves digitization of all the details of ration card and Adhaar card holders and linking it with their bank accounts. The procedure is aimed at hassle-free transfer of funds only to the authorized beneficiaries and not to people who currently get undue benefit of government subsidies.

\section{Related work}

The vital part in FPS is identification of valid costumer, weighing and selling grocery by the dealers. There are many conventional methods available of weighing scale. Weighing scales are devices to measure weight or calculate mass.

A. Old weighing machine:-

Spring balances measure weight by balancing the force due to gravity against the force on a spring, whereas a balance or pair of scales using a balance beam compares masses by balancing the weight due to the mass of an object against the weight of a known mass. Either type can be calibrated to read in Newton, or in kilograms.

\section{B. Digital Weighing machine:-}

Now days the demand of digital weighing machine increasing day by day because measuring the weight with digital weighing machine is user friendly with variety of various applications. The design and implementation of high resolution advanced digital weighing scale design based on 2-bitsigma-delta ADC along with fully featured embedded system.

Proper weighing and ethical selling of food grain is necessary for the people of below poverty level. Many illegal cases have been occurred at Rashan supply shops.

"Panchanama of ration supp lied to shops to prevent corrupt practices" [1]

NEWS BY-Abhilash Botekar | TNN | Dec 14, 2015.

NASHIK: After Rs 7-crore scam in food grains supplied to below poverty line card holders through various fair price shops under public distribution system rocked Surgana tahsil of Nashik district in January 2015, the administration took up several measures to ensure discipline among the shopkeepers.

"License of corrupt fair price shop owner cancelled" [2] TNN | Feb 12, 2012, 01.44 AM IST

GONDIA: Villagers of Powaritola in Gondia district ended their eight-day long relay hunger strike after their demand for cancellation of licenses of the dealer of kerosene and fair price shop on grounds of corruption was conceded.

"Corruption in PDS will be non -bailable offence"NEWS BY- Girish Bapat. [3]

The government has introduced biometric system to curtail the bogus ration cards." Minister for Food and Civil Supplies Girish Bapat said corruption in disbursement of subsidized food grains and kerosene for fair price shops would be made a non-bailable offence.The ministry will put the proposal before the cabinet.The government has introduced biometric system to curtail the bogus ration cards.But it has come to notice that often food grain meant for ration shops is diverted in open market by middlemen.Anybody found indulging is corruption would be subjected to punishment.

To avoid such kind of frauds a smart system is implemented referring to government ${ }^{\text {ec }} \mathrm{s}$ idea of biometric system i.e. fair price shop tracking system.

\section{Working methodology}

In the fair price shop tracking system consists of AT89s52 Microcontroller, thumb detector GSM module etc. Microcontroller plays essential role in this system. The 


\section{International Journal of Science and Research (IJSR) \\ ISSN (Online): 2319-7064}

Index Copernicus Value (2013): 6.14 | Impact Factor (2014): 5.611

overall circuit works on $5 \mathrm{v}$ power supply. There are four push buttons are provided for user entry.

1) $1^{\text {st }}$ button is to enterthe requirementin $\mathrm{Kg}$ and to withdraw,

2) $2^{\text {nd }}$ button is provided to enter the identity of a new person,

3) $3^{\text {rd }}$ button is for deleting the particular person ${ }^{\text {ee }} \mathrm{s}$ information and to increment the weight of ingredients,

4) $4^{\text {th }}$ button is to decrement the weight.

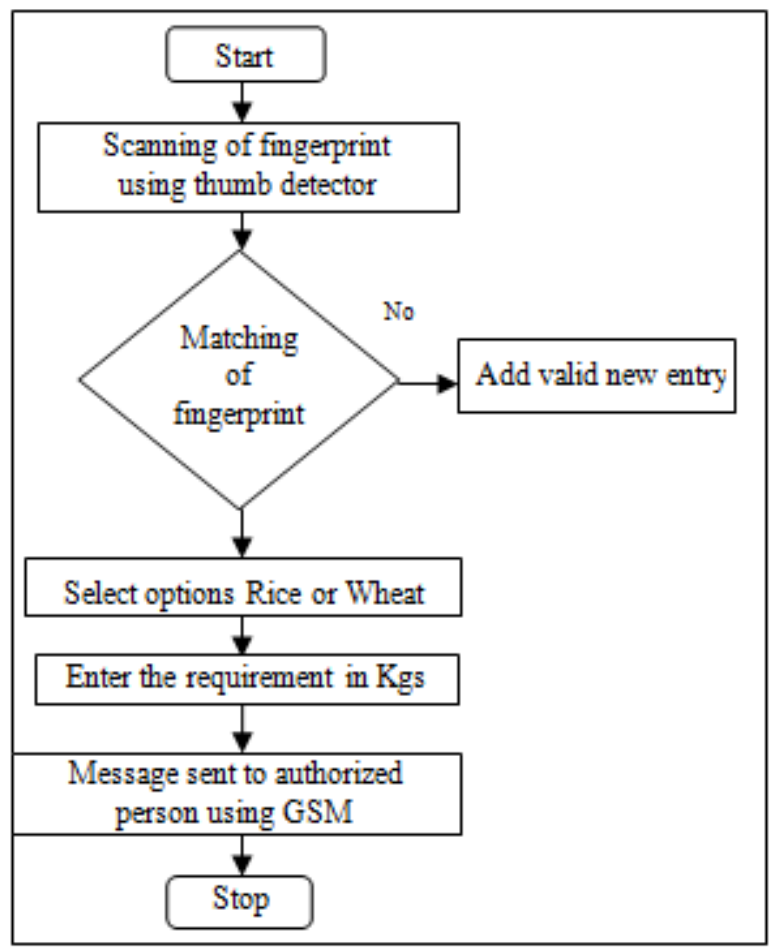

Figure 1: Flowchart of FPS system

Here the thumb detector is used to keep record the identity of an individual customer. It is interfaced with microcontroller. When a customer comes to fair price shop then he or she gives their thumb impressions which are saved in the memory of a microcontroller. When a customer comes to shop then the thumb detector verifies the thumb impression with pre-scanned thumbdata. When it matches then there are three options are made available whether to withdraw, add or delete.If the thumb impression is already stored then press $1^{\text {st }}$ button for withdrawal. As soon as we press the $1^{\text {st }}$ button then two options on LCD are displayed. $1^{\text {st }}$ is Rice and $2^{\text {nd }}$ is wheat, select the option and then press Enter ( $1^{\text {st }}$ button) then immediately a message of withdrawal is sent on stored number by using GSM.

If the thumb is not matched then new entry is done by pressing $2^{\text {nd }}$ button which contain, add ${ }^{\text {ee }}$ option and the next steps are continued. Each customer is provided with a unique identity number.

\section{Hardware description}

The hardware part of the system contains thumb detector, power supply, GSM module, LCD display.

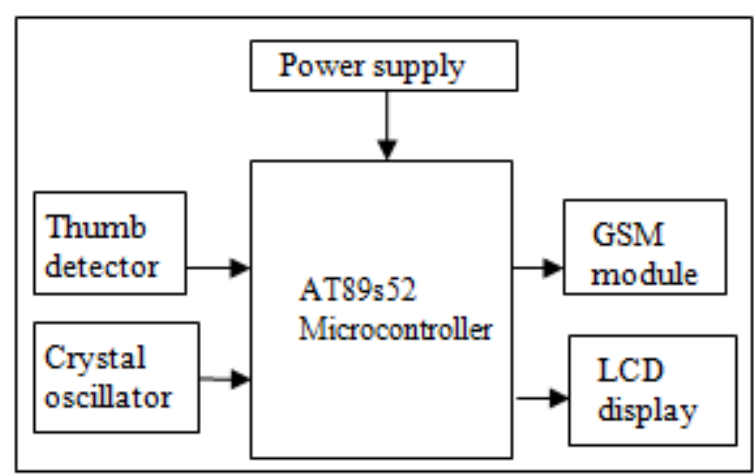

Figure 2:Block diagram of FPS

\subsection{AT89c51}

The AT89C51 is a low-power, high-performance CMOS 8bit microcomputer with $4 \mathrm{~K}$ bytes of Flash programmable and erasable read only memory (PEROM). The device is manufactured using Atmel's high-density nonvolatile memory technology and is compatible with the industrystandard MCS-51 instruction set and pin out. The AT89C51 provides the following standard features $4 \mathrm{~K}$ bytes of Flash, 128 bytes of RAM, 32 I/O lines, two 16-bit timer/counters, five vector two-level interrupt architecture, a full duplex serial port, on-chip oscillator and clock circuitry.

\subsection{GSM}

The Global System for Mobile Communications (GSM) is the most popular standard for mobile phones in the world. The key advantage of GSM systems has been higher digital voice quality and low cost alternatives to making calls such as text messaging. The advantage for network operators has been the ability to deploy equipment from different vendors because the open standard allows easy inter operability.

\subsection{SIM}

One of the key features of GSM is the Subscriber Identity Module (SIM), commonly known as a SIM card. The SIM is a detachable smart card containing the user's subscription information and phonebook.

\subsection{Thumb detector}

A thumb detectoror fingerprint scannersystem has two basic jobs 1 ) it needs to get an image of a consumer's finger, and 2) it needs to determine whether the pattern of ridges and valleys in this image matches the pattern of ridges and valleys in pre-scanned images.Only specific characteristics, which are unique to every fingerprint, are filtered and saved as an encrypted biometric key or mathematical representation. No image of a fingerprint is ever saved, only a series of numbers (a binary code), which is used for verification. The algorithm cannot be reconverted to an image, so no one can duplicate the fingerprints.

\section{Software Description}

The coding part of the microcontroller AT 89s52 is done in C programming using Keil uvision software. This Simulation helps to understand hardware configurations and avoids time 


\section{International Journal of Science and Research (IJSR) \\ ISSN (Online): 2319-7064 \\ Index Copernicus Value (2013): 6.14 | Impact Factor (2014): 5.611}

wasted on setup problems. Additionally, with simulation, one can write and test applications before targethardware is available. Program is burnt into the IC using Flash magic tool and IC burner kit.

\section{Experimental validation}

The performance of the proposed control approach is validated with aid of laboratory prototype that has system parameters shown in table 1.

Table 1: System parameter

\begin{tabular}{|c|c|}
\hline Step down transformer & $1 \mathrm{~A}$ \\
\hline Thumb detector & R305 \\
\hline GSM & SIM300 \\
\hline Mains & 230 V \\
\hline LCD & PC1602A-L \\
\hline
\end{tabular}

Based on the hardware description and flowchart the system of fair price shopping system is built. The hardware model of proposed system is shown in figures given below.

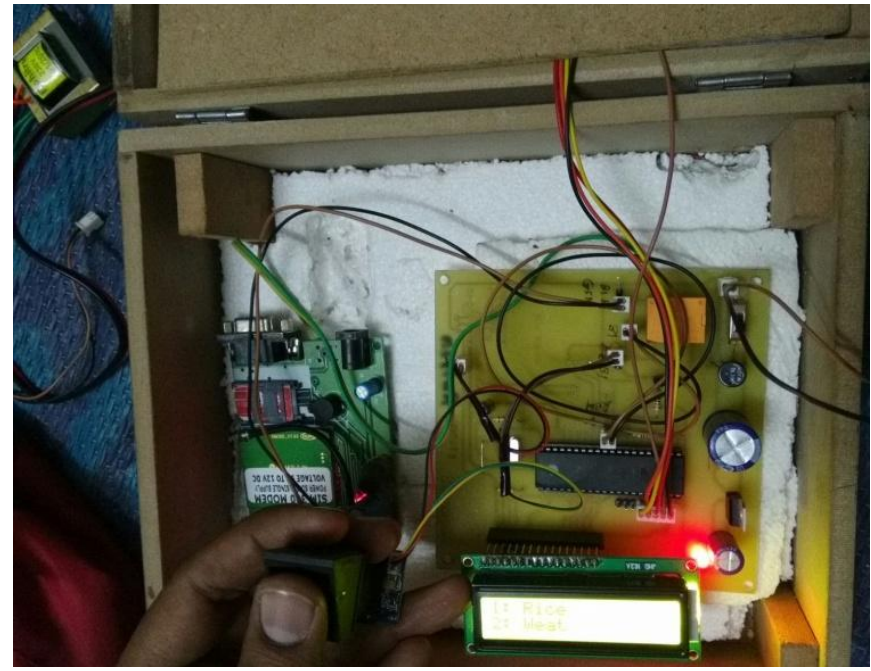

Figure 3: Scanning of thumb impression

Given figure shows the experimental set up of fair price shop and overall procedure of selection of options, withdrawal of grains and its record.

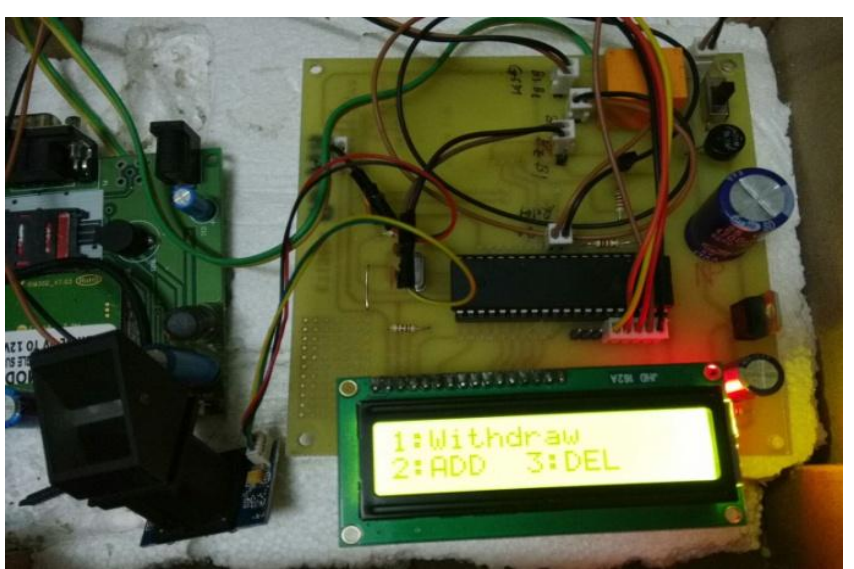

Figure 4:Selection of options

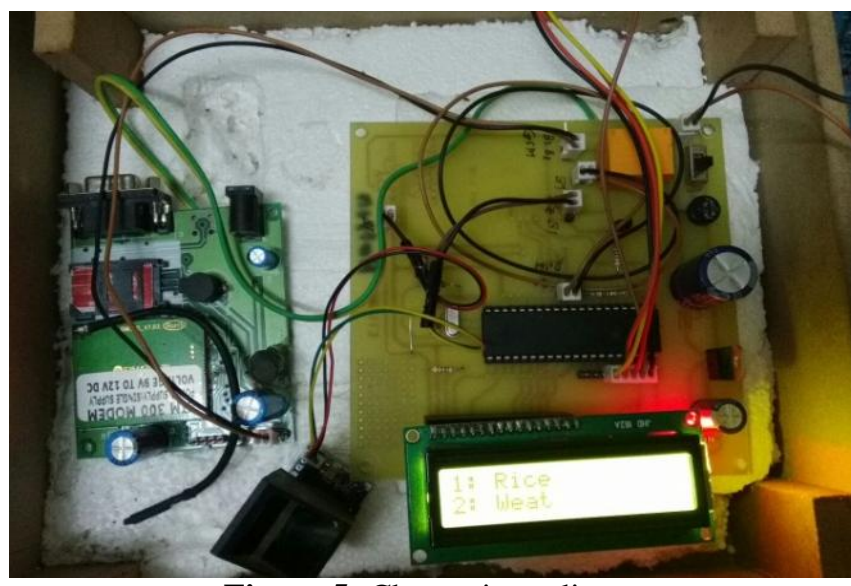

Figure 5: Choose ingredients

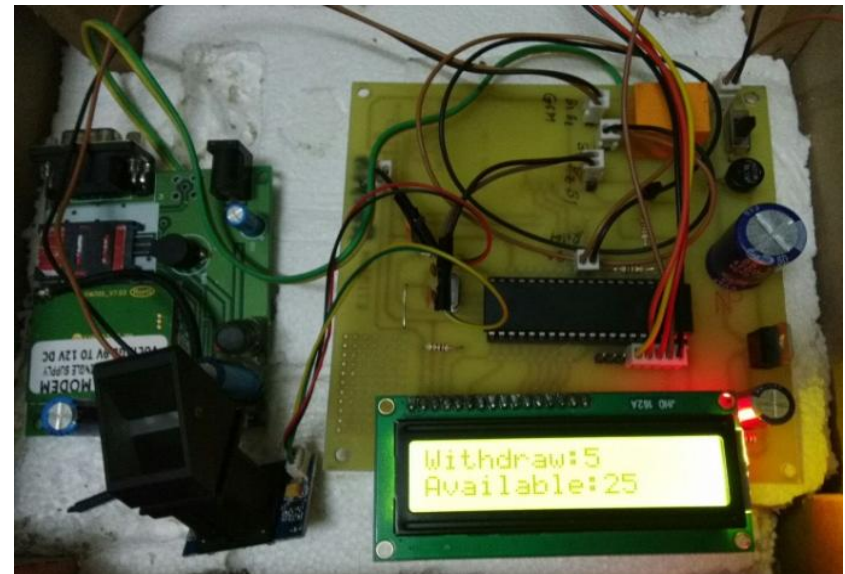

Figure 6: Message sent to mobile

\section{Conclusion}

Basically this system is implemented by considering the need of below poverty line (BPL) card holder to get their food grain without interferes. The fair price shop system is simple user friendly and compact. The foremost purpose of ,anticorruption ${ }^{\text {ee }}$ is achieved using this system. Customer or non technical person can also track information about the balance available on their account and messages can preserve as a proof for higher authority. As the use of paper is avoided so deforestation is avoided. This will help to balance the Indian economy system and also supports "smart city" and "make in India" mission of Prime Minister "Narendra Modi".In future this real time operating system can be used in locker system, for security (one account is accessible to multiple authorized persons) and also it will replace the use of ATM card by using thumb detector. Also the acknowledgement mechanism can be included from higher authority.

\section{References}

[1] Abhilash Botekar, "Panchanama of ration supplied to shops to prevent corrupt practices", | TNN | Dec 14, 2015.

[2] "License of corrupt fair price shop owner cancelled"TNN | Feb 12, 2012, 01.44 AM IST

[3] Girish Bapat, "Corruption in PDS will be non-bailable offence", Times of India.

[4] Nikhil Deshmukh, "Date extended for biometric system in fair price shops" | TNN | Mar 26, 2015, 06.47 AM IST. 


\section{International Journal of Science and Research (IJSR) \\ ISSN (Online): 2319-7064}

Index Copernicus Value (2013): 6.14 | Impact Factor (2014): 5.611

[5]M. A. Mazidi, “The 8051 microcontrollers and embedded systems", Pearson publication.

[6] J. W. Valvano, "Embedded microcontroller systems real time interfacing", Cengage learning publication.

\section{Author Profile}

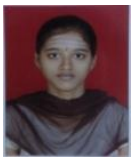

Pooja Hulgeri pursuing the Diploma in Electronics and telecommunication engineering from Shri. Siddeshwar Women"s Polytechnic, Solapur.

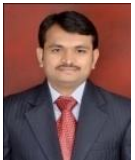

Pramod Shivgunde received the BE degree from Pune universityin Electronics and Telecommunication engineering and M.Tech. in Embedded system from JNTU in 2015. Currently working as a Professor in Shri. Siddeshwar Women"s Polytechnic, Solapur.

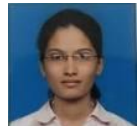

Rajanigandha Metri received the $\mathrm{BE}$ degree from Solapur university in Electronics and Telecommunication engineering and M.E. in Signal processing from Pune University in 2014. Currently working as a lecturer in Shri. Siddeshwar Women"s Polytechnic, Solapur. 